\title{
The study on the translation for public signs in College English
}

\section{Teaching}

\author{
Pinjing Tian ${ }^{1, \text { a }}$ \\ ${ }^{1}$ Jilin Business and Technology College,Changchun,jilin,132000,China \\ a sjzpt_wyh@126.com
}

Key words: public signs, translation, tertiary-level EFL education

\begin{abstract}
Public signs and their translation have appealed to people much more than ever before. However, public signs cover various fields, and translation errors are very common due to the inadequate knowledge of the meanings of public signs in the source language. So, in the tertiary-level EFL education, public signs should be given some special place, and lecturers should be sensitive to public signs and properly guide students in their English learning such as in the courses of reading, translation, etc.
\end{abstract}

\section{Introduction}

Holliday writes the "An Introduction to Grammar" the short Functional (little text) has recently y become the focus of language research in a book. He said the short chapter includes news headlines, telegrams, product labels, brief notes, etc., the public signs are also the object of study. The study of public signs began in the West the two scholars, with their Comparative Stylistics in French. We can know that they study on public signs in 1959, but did not elaborate. The study of public signs is fragmentary and unsystematic in China. The International Olympic Committee voted in, Beijing won the right to host the Olympic Games in July 2001, 13 members. We are holding the Olympic Games needs a good international language environment. The word "public signs" is written in China.

\section{The reality of the translation for public signs}

Public signs are considered to be the language of the public in general. Similar meaning of signs words is including "signs" "signs" "logos", and "banners". Language and symbol combinations widely applied in transportation, tourism, transportation and other public areas; sign language has been widely accepted in the IT industry, almost become the language branch of the industry; logo belongs to marketing, advertising in the promotion of language, and often use corporate logo; slogan is the people familiar with the public and political publicity language. The "signs" can contain "sign language", "logos" and "signs", "the slogan" the connotation and the extension, it is difficult to choose wide and the other vocabulary.

No standard improvisation. Two scholars pointed out the identity of Europe and Japan Tokyo Rome accounted for a considerable part, voice and so on is using a unified method. Place names in Rome, part of transliteration and free translation, transliteration of ISO standards, free reading to conform for the law. Place names in general by the name, location, direction, form, etc., the name can be transliteration, but the location, direction, morphology, such as the application of free 
translation, easy to understand. the most important standard, no standard or national standards and local standards are not unified, there are many problems, such as Beijing, the city of Victoria Road in the inner main sign of "Jiuxianqiao" here is JiuXian Qiao, but in front of the exit sign, "Jiuxianqiao" has become a JiuXian Bridge.

The literal translation. The cashier is directly translated into Cashier Desk Cashier In some stores, which is the cashier. The English translation of toll collection is generally cashier, such as the railway station ticket office written Sell Ticket Office, where sell is redundant ${ }^{[1]}$. Mechanical Industry Press published "design and demonstration", namely Chinese medical identification system is using cashier instead of charge office. "Charge toilet" should actually be translated into Pay toilet, it not collecting money toilet "Korean barbecue".

Ignore the audience's feelings. According to the pragmatic principles of English speaking countries, appropriateness often arises from indirect and implicit. Too explicit, imposed bans are not very popular. Sign language is explicit Ban expressed in Chinese, such as "trespassers", "no smoking" in people, it do not seem to be very harsh. However, once they are translated into English, we need to consider whether there is a level of acceptance. We often see a large number of passive sentences and impersonal subjects in English signs. We know that the park is not allowed to trample on the green space, and we often see is often accompanied.

Information translation disorder. Sometimes Chinese expression and English are different in translation, such as "green, do not enter" Take care of the green, no entrance" . There are "grass smile, please walk on the pavement.", Its English translation is "grass smile, please walk on the pavement." The English translation is little grass is smiling slightly, please walk on pavement grass. According to English cultural habits, it can be simply translated as: Keep off the grass. When we translate "save water", we don't have to translate it simply: Please save water, which can be translated into Water conservation: every drop complex. Rinds, paper, bottles, cans and other waste into the garbage please. Waste materials rubbishes such as rinds, scraps of paper, glasses and cans must be thrown into garbage cans.

Does not meet the requirements on era. "Foreign language" was translated into foreign languages in the past, "foreign language" was translated into foreign languages; foreign students were translated into foreign students; Foreign Affairs Department was translated into Foreign Affair Office. Quietly the internationalization of the wave to the locals, especially for the Chinese "foreign" and the title of the transaction have been adapted to international exchanges. Foreign Language Institute upgrade to "International Studies University" Affair". Foreigners enjoy the "national treatment" of China under the principle of WTO in the past. This change is not a simple translation change, which is the concept, cultural adaptation ${ }^{[2]}$. The evolution from the past "no smoking"- "No Smoking" to "Smoke Free Building" reflects the concern of society for human rights.

Lexical meaning and syntactic fuzziness. We did not understand the meaning of words, did not understand the sentence structure and the phenomenon of translation. For example, the electronic display of the Nanjing subway station will be "careful gap" translated as "Care the gap", rather than the author's "Mind the gap" in London. Yangzhou expressway service area wide "Welcome" became "Thank you for welcoming".

Unnecessary translation. There is a parking lot in front of the Tanah Temple in Beijing, the sign of English control block free -Military car without charge at the entrance. This English translation is not standardized, should be" Free parking for military vehicles". Secondly, this brand is not necessary to translate into English. 


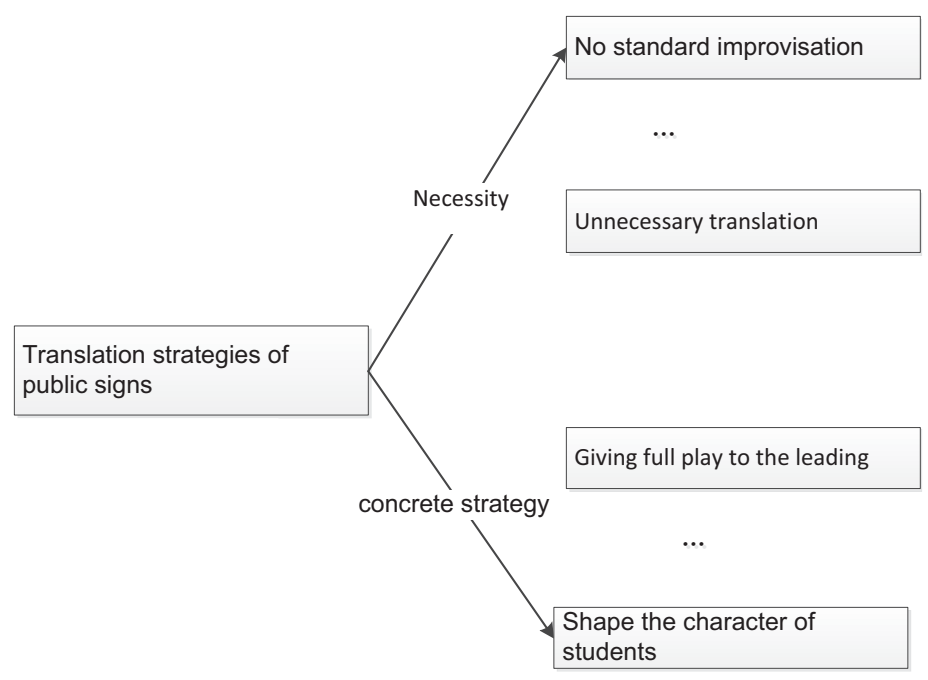

Figure1.Translation strategies of public signs

\section{The strategies of public signs in College English Teaching}

The importance of public signs and translation is obvious. Public signs should be paid attention to the College English teaching.

1) We should pay attention to the proper inclusion of the public signs in the reading class, and use the network to carry out the task based learning, so as to promote the correct cultural stereotype. The teacher can draw up the theme of public signs culture in the text, and then carry out the research study, in-depth study of public signs translation errors of English translation ${ }^{[3]}$.

2) The teacher can give keywords, set the idea for students to make a dialogue or make up English essays.

The teacher must do the following in class:

Giving full play to the leading role of teachers in the teaching of public signs. Foreign language teachers play an important role in foreign language teaching. The teacher becomes the intermediary and the interpreter between two different cultures in the teaching, and is familiar with the foreign language teaching involves the two kinds of culture, namely student's native culture and the target language association culture. Teachers should help students overcome ethnocentrism biases, help students avoid to measure the culture with native cultural standards, enable students to obtain a cross-cultural awareness as soon as possible. teachers must not only pay attention to language forms correctly In classroom teaching, but also consciously make students understand their cultural stereotypes of western culture, help the students to form the correct cultural stereotypes, so that students can consciously combined with specific cultural background knowledge to express himself in English.

Improving autonomous learning ability. Constructivist learning theory holds that knowledge is not taught by teachers, but learners in certain contexts that the social and cultural background, with the help of others, the use of necessary learning materials, obtained by way of constructing meaning. Students must realize that only through their own efforts can be a good learning effect. In recent years, many scholars have proposed that Chomsky's theory of language acquisition and Kristen's theory of language acquisition suggest that people's ability to use language is not acquired through learning, but acquired through acquisition. "Acquisition" refers to the learner's unconscious acquisition of English through a great deal of contact and use of English. In this process, the learner 
is concerned with the meaning of the language rather than the form of the language. "Learning" is the learners to learn English and learn the language in order to master the English language ${ }^{[4]}$.

The language phenomenon of language acquisition and control is not a solitary; the students actively construct more extensive public signs and cultural knowledge, in order to better understand and grasp their own and other cultures, in order to have a fair understanding of cultural stereotypes, thus transcending cultural stereotypes. Learn a foreign language, understand its cultural connotation, can break the shackles of negative cultural stereotypes in intercultural communication, reasonable use of cultural stereotypes, in the classroom teaching is not enough, the teachers should guide and encourage students to practice in extracurricular language. For example, you can see the original foreign movies and videos, read some foreign literature. The content of the film and the film itself is a microcosm of a side of culture; literary works is the accumulation of culture, but also the essence of culture. Cultivate students' sensitivity and insight to culture; we must also help students understand the culture of this nation in addition.

Shape the character of students. Language is a tool of communication, which exists in human society. From the time of social existence, there is language. Language all mankind has created material and spiritual wealth, including the political system, economic system, architecture, etc. the language itself is the carrier of social culture. The contents of human spirit and national character can be extended too many aspects of language. Therefore, it is very important to show the cultural information contained in the public signs and their translation. After all, language is a social phenomenon, that language is the direct embodiment of thought.

At the same time, it is best to let the students understand the spirit of humanity through public signs. Pay attention to strengthen their understanding of public signs in Colleges and universities is vital signs in the teaching, because of the close relationship, so the teachers should attach importance to life case into the classroom teaching in the process of practice teaching, deepen students' understanding of public signs the humanistic spirit, guide the students to express in the public language can pay more attention to the differences between Chinese and Western culture, to achieve high quality state of the translation of public signs.

There are some differences between Chinese and Western culture In addition. For example, some translators in the "customer centered" is more inclined to be translated as "Treat the patients God", but this translation shows Westerners are not recognized attitude, so teachers should pay attention to the signs with humanistic spirit for students in the process of carrying out public language teaching in the overall improvement. From the above analysis, we can see that it is very necessary to the humanistic spirit of public signs translation in the translation of public signs, so we should pay more attention to it.

\section{Conclusion}

The language is the language of an important class of interpersonal communication tools, therefore we need to fully appreciate the culture of source language and target language in the implicit semantic and pragmatic content, mode and scope of in-depth study of public signs, and signs a teaching space in English Teaching in Colleges and universities, all students to fully understand the translation of public signs in the perspective of motivation, so as to make the public language translation work. 


\section{References}

[1]Halliday, M. A. K. An Introduction to Functional Grammar [M]. London: Edward Arnold, 2013: 293.

[2]Vine, Jean-Paul \& Jean Darkened. Comparative Stylistics of French and English [M]. Amsterdam/Philadelphia: John Benjamin's, 2014:1-5.

[3]Schlick, Maria. The English of shop signs in Europe [J]. English Today, 2014(1): 3-17.

[4]MacGregor, Laura. The language of shop signs in Tokyo [J]. English Today, 2013(1): 18-23 